\title{
Promoting Intellectual Community and Professional Growth for a Diverse Faculty
}

\author{
Dorothe J. Bach, Marva A. Barneft, \\ José D. Fuentes, Sherwood C. Frey \\ University of Virginia
}

Minority faculty retention is key to increasing faculty diversity at most colleges and universities. Because retention depends on individual faculty choice and administrative tenure decisions, institutions need to help junior faculty develop a tenurable profile and enhance their desire to remain at their institution. This chapter examines a fellows program that supports beginning faculty in developing successful long-term careers, taking into account research on helping diverse faculty members thrive. It also presents strategies for establishing viable peer support networks and partnerships with senior consultants and for creating programming that ensures new faculty successfully transition into teaching, research, and the university community.

\section{Introduction}

Women and minorities who make unadaptive starts in the professoriate evidence a series of reliable turning points early in their career, typically within their first few semesters on campus... The simple nature of these turning points also implies strategies for preventing or reversing the disappointing and marginalizing beginnings so common for nontraditional hires. (Boice, 1993a, p. 71)

The new perspectives and approaches (often interdisciplinary) brought by faculty from diverse backgrounds help invigorate and stimulate the intellectual 
environment. If institutions of higher education are to provide students from increasingly diverse backgrounds with diverse faculty role models, they need to improve their hiring practices and their strategies for retaining new hires. Although sometimes successful retention depends on factors outside university administrators' immediate control, research by Austin (1990), Boice (1993a, 1993b), Fink (1992), Olsen and Sorcinelli (1992), Sorcinelli (1992), and others shows that institutional support early in professors' professional lives has a significant impact on their decision to stay at or leave their institutions when new opportunities arise. A close look at crucial career turning points suggests that specific interventions can help prevent the all-too-common frustrations and early disillusionment experienced by nontraditional faculty. Faculty developers are often in a position to facilitate appropriate interventions. In designing the Excellence in Diversity Fellows Program for incoming and second-year faculty at the University of Virginia, steering committee members kept clearly before them the importance of the early turning points for women and minority faculty members that Boice (1993a) identified in his research: collegial isolation, rejection by students, and stresses of marginalization.

The University of Virginia and the University of Colorado (Alire, 2002) are two of the few state universities where retention programs have been implemented. Since U.Va. adopted diversity as a core value in 2002, members of the Teaching Resource Center have worked closely with administrators and senior faculty to develop the Excellence in Diversity Fellows Program with one main goal: that new faculty members remain at the university as productive scholars. The assumption is that the University of Virginia hires excellent faculty members; it is in the interest of the university to support their successful professional development. In addition, of course, by diversifying the faculty, the university can provide better role models to our diverse undergraduate student body ( $25 \%$ are students of color and international students; $54 \%$ are women).

\section{Faculty Diversity as a National Issue}

African Americans, Hispanic Americans, other people of color, and women continue to be woefully underrepresented in a number of academic disciplines (particularly in science and engineering) and in the professoriate (National Science Foundation, 2000b), as well as at institutions of higher education in general. Thus the wider academic community is not taking advantage of the talents and skills of an increasingly large segment of society. Underutilizing talent in this way has clearly detrimental societal consequences: an educated 
workforce representing all segments of society is crucial for social well-being and essential for competing in the current and future global economy. In fact, "the recent U.S. census showed the changing demographics of the country. The data make it clear that the underrepresented minority is becoming the underrepresented majority" (Morrissey, 2002, p. 24). Academic institutions, professional societies, and federal government agencies all need to take leadership in developing and coordinating innovative strategies to meet the challenges of this major culture change.

The Excellence in Diversity Fellows (EDF) Program is rooted in the tenet that university faculty members in the United States play a fundamental role in preparing and shaping future generations of those who contribute to society at all levels. Faculty members serve as professional and citizen role models and thus influence young people's career expectations. At a time when our student bodies are becoming more diverse, the lack of role models is felt acutely. Sadly, the relatively few diverse faculty members who pursue academic options are often dissatisfied with their initial experiences and leave their universities in search of a more welcoming institution, or they abandon academia completely in favor of a career in business or industry.

The EDF Program explicitly targets this failure to retain promising individuals by directly responding to the challenges these junior colleagues face at the beginning of their careers. Since research has shown that networks of mentors and peers are often not as accessible to nontraditional faculty as they are to majority groups, the program proactively alleviates collegial isolation by ensuring prearranged networks of support (Boice, 1993a). Committed mentoring and strong peer and extended networks provide incoming colleagues with opportunities for greater intellectual discourse among junior faculty members and between junior and senior faculty members who act as mentors. Through such a mentoring program and by offering incoming faculty key information about strategies for success, we aim to assure them that they can develop successful and rewarding academic careers. An additional assumption underlying the EDF Program is that nontraditional faculty members are motivated to remain in academe when they develop a sense of belonging to an institution and feel wanted for their academic contributions (Boice, 1993b; Hale, 2004; Sorcinelli, 1992).

Certainly, programs such as EDF should be viewed as part of a broader, national effort. In the recent past, federal government agencies and professional societies funded strategies to improve the representation of minority groups such as African Americans, Hispanic Americans, and women in the professional ranks and in all levels of the education spectrum, ranging from $\mathrm{K}-12$ education to the doctoral level (National Science Foundation, 2000a). 
Today, in a climate where national funding for minority programs is being eliminated, programs such as EDF can make a significant difference in realizing the goal of universities to offer an inclusive liberal education and serve all members of society.

\section{Faculty Diversity at the University of Virginia}

The current situation regarding diversity at the University of Virginia (U.Va.) is unique only insofar as the university's particular history has amplified some of the challenges that research institutions in general face as they strive to diversify their campuses. As a state university, U.Va. was one of the last to lift its restrictions regarding the admission of African American and women students. Although the first black student was admitted to the School of Law in 1950-after attorneys of the National Association for the Advancement of Colored People sued the university - it was another 20 years before the university's containment policy was finally abandoned in 1969 in the face of protests of a coalition of radical, liberal, and moderate students. Because U.Va. has a longer history of race- and gender-based exclusion than most other institutions, it offers a good test case to assess the effectiveness of administrative interventions designed to remedy persistent inequalities.

Over the past 30 years, the U.Va. has continually increased on-campus representation of women and minority students. Women now comprise $54 \%$ and African Americans $8.8 \%$ of the undergraduate student population. The percentage for African Americans compares relatively well with that of peer institutions. For example, the University of North Carolina-Chapel Hill enrolls $11.1 \%$ African American undergraduate students, the University of Michigan enrolls $7.8 \%$, and University of California-Berkeley enrolls $3.8 \%$.

In addition, for the past 10 years, the University of Virginia posted the nation's highest African American graduation rates among major public institutions (Cross, 2003). With a graduation rate of $85 \%$, U.Va. takes a clear lead among state-chartered institutions in the nation, followed by the University of New Hampshire and the University of North Carolina-Chapel Hill at $66 \%$, and the University of California-Berkeley and the University of Delaware at $64 \%$. This success is a result of administrative commitment and progressive programs such as the Office of African-American Affairs Advising Program, which matches black upperclassmen with black freshmen to make both academic and social transitions easier.

Although the University of Virginia has made considerable progress in helping African American students feel welcome and supported academically, 
it has not so successfully hired and retained minority faculty. According to the report of the U.Va. President's Commission on Diversity and Equity, the upper echelons of the university's faculty and administration are still overwhelmingly white and male, while females and minorities are aggregated in lower-paid areas such as clerical and custodial positions: women represent only $13 \%$ of full professors, and African Americans only 2\% (Davis \& Smith, 2004). Both groups are overrepresented in lower-level and in nontenure-track faculty positions. The numbers have stayed relatively flat since 1998, despite the increasing attention that has been given to matters of diversity (Davis \& Smith, 2004).

U.Va's situation is indicative of a crisis facing most research institutions in the nation.

While the nation is doing a good job of turning out women with research doctorates, the top 50 institutions in research spending are not doing such a good job of hiring them. Other recent research shows that women at doctorate-granting universities advance more slowly on the tenure track than men do, are paid less than their male counterparts, and are more apt to be dissatisfied with their jobs. (Wilson, 2004, p. A8)

The U.Va. President's Commission on Diversity and Equity worked to determine the status quo in regard to diversity at the university and to coordinate the change initiatives created when diversity was first adopted as a core value in 2002. The Excellence in Diversity Fellows Program is one such initiative. It is currently funded by the provost and by the deans of arts and sciences, engineering, and medicine. It has been cited by the co-chairs of the President's Commission on Diversity and Equity as a "best practice" and a "vital component of our collective efforts to attract and retain faculty from underrepresented populations" (Michael Smith, personal communication, October 31,2004$)$. It is an example of the work that can be achieved with support from an institution's leadership.

\section{Program Goals and Assumptions}

In an effort to help new faculty navigate early career challenges and promote their long-term development as productive scholars, the Excellence in Diversity Fellows Program cultivates these colleagues' connection to the university. It thereby supports the university's larger vision of invigorating the institution's intellectual climate by improving the retention rate of diverse faculty members, particularly those dedicated to working with our increasingly 
diverse student body. The program's mission statement stresses that learning and understanding others' values and ways of thinking is integral to the educational process in an increasingly heterogeneous society. We believe that the intellectual vitality and well-being of our students depends in great measure on having a faculty whose perspectives span and envelop the cultural, ethnic, and scholarly traditions and interests of the entire "academical village." Our particular assumptions about faculty retention that underlie the Excellence in Diversity Fellows Program come from a variety of sources: our personal experiences (both as diverse faculty members and as colleagues of diverse faculty, some of whom have left the university and told us why); research on faculty retention; and knowledge derived from a previous, related endeavor, the University Teaching Fellows Program. The Excellence in Diversity Fellows Program is based on the following key assumptions:

- Faculty are more likely to find their place within the university when they feel broadly valued and appreciated in ways such as these:

They believe they contribute.

$\sim$ They feel successful and valued in their research and teaching.

- They have effective mentors and confidants.

$\sim$ They see progress in their careers.

They interact positively with senior colleagues.

$\sim$ They feel recognized for their contributions.

- Committed mentoring and strong peer and extended professional connections are essential to the professional success of faculty. Research has shown that networks may not be as accessible to nontraditional new faculty as they are to those from majority groups. Such collegial isolation, one of the main reasons for early career disillusionment, can best be avoided by ensuring prearranged networks of support and mentoring (Boice, 1993a).

- Because retention depends on individual faculty choice and administrative tenure decisions, this program helps junior faculty develop a tenurable profile and enhances their desire to remain at U.Va.

- As a result of recommendations from the U.Va. President's Commission on Diversity and Equity, we expect that administrators and senior faculty will work increasingly with diverse faculty and will benefit from direct and constructive interaction with those colleagues. In addition, 
junior faculty will gain insights into policies and procedures and will develop greater confidence and comfort in communicating with their senior colleagues.

Since the main goal of the EDF Program is to improve retention of faculty members who contribute to the overall diversity of our faculty, the program's activities aim to address the challenges identified in the research. Ensuring prearranged networks of support and mentoring has had a strong impact on the following program objectives:

- Offer new junior faculty direct, early insights into how to succeed in the academic world, including engaging them in defining their teaching and research agendas

- Promote a peer-level support network and serious intellectual discourse among a diverse group of faculty members

- Initiate and support productive interactions between fellows and the senior faculty (senior consultants) who serve as knowledgeable, generous mentors, thus deepening and broadening their connections to colleagues and to the institution

- Offer senior faculty opportunities to share and develop their mentoring skills

- Foster improved interactions among junior and senior faculty members and academic administrators

- Support faculty in teaching students from diverse backgrounds and in creating inclusive learning environments

- Establish and maintain an environment in which junior faculty, particularly those from diverse backgrounds, develop a sense of belonging to a community, not only within individual academic units but also to the university as a whole

- Offer senior faculty and administrators insights into perspectives and concerns of diverse faculty members

\section{Application Process}

We encourage applications from all junior faculty who will begin their first or second year as tenure-track assistant professors at U.Va. during the fellowship period and who are interested in connecting with both university colleagues 
and our increasingly diverse student body. We particularly solicit applications from faculty from underrepresented groups (including but not limited to first-generation college graduates, women faculty, faculty of color, and international faculty) and from faculty whose research interests may not fit traditional organizational frameworks. Senior faculty and chairs are urged to encourage candidates to apply and to utilize this program as part of their junior faculty development initiatives.

To solicit applications from as many interested faculty as possible, we keep the application form simple and short. Besides basic information, we ask applicants to answer multiple-choice questions regarding their research and teaching interests as well as what they seek in a mentor in order to better match them with their mentoring consultants. Other questions include: What are your short-term scholarly goals (for the next two to three years) related to teaching and research? What do you see as the benefits of being on the U.Va. faculty and a participant in the EDF Program? What are your plans for and concerns about a successful career, including strategies for connecting your teaching and research to U.Va.'s diverse student body? What benefits would you like to gain from working with one or more mentors, colleagues with more experience at U.Va.? (A complete application form can be found at http://trc.virginia.edu/Programs/EDF/EDF.htm.) In 2003, we received 19 applications for eight fellowships. In 2004, we were able to expand the program and offer 14 fellowships, for which we received 26 applications from a pool of 60 invited new faculty members.

In reviewing applications, the EDF steering committee considers each application carefully and makes individualized decisions based on a broad range of criteria that include the following:

- Applicants' diverse backgrounds including, but not limited, to academic disciplines, research and teaching interests, personal achievement, leadership, socioeconomic background, minority identification, special skills and talents, and unique experiences

- Date of terminal degree and any previous years of experience as assistant professor

- Potential for serving as a teacher and mentor as well as interest in and capacity for connecting their teaching and research to diverse students at the university

- Level of complexity and interdisciplinarity of applicant's research and teaching interests and goals 
- Commitment to fully participate in an academically and culturally diverse peer group

- Plans for developing a productive long-term career at U.Va.

- Acknowledgement of challenges and concerns regarding early career development

- Potential benefit to each candidate from participation in the EDF Program

In addition, to the extent possible we take into account shared as well as diverse backgrounds, plans, and concerns when composing the groups of fellows; that is, we look for ways to create a connected group of fellows. For example, all other things being equal, we might select two candidates from different backgrounds and disciplines who both have research interests in the impact of violence. We have found that such commonalities help the group bond.

\section{Program Activities}

Each year, steering committee members work to tailor the monthly events to fellows' specific needs, while consistently offering them the information and mentoring research has shown to be helpful (Boice, 1993b). During their year in the EDF Program, fellows gain insights into their roles as professors and learn about the university both through group activities (including a retreat followed by seminars, workshops, and discussions) and through individual consultations and conversations with their senior consultants. They may also each apply for up to $\$ 1,000$ funding for at least one professional development opportunity (e.g., travel to professional conferences, seminars, or workshops; curriculum development projects; student assistant support).

\section{i Retreat}

Early in the semester, fellows accompany members of the program steering committee on a day-long retreat away from the university, preferably in a rural setting conducive to relaxation. There, the fellows from a wide variety of academic disciplines-most of them new to the university-get to know each other, each one introducing another in terms of educational background, research and teaching interests, and interests/life beyond the academy. Since Boice (1993a) has found that events very early in assistant professors' careers can color their feeling about the institution and affect their sense of belonging, 
we offer a positive, connecting experience as quickly as possible. One goal of the retreat is to reduce the feeling of isolation so common to new faculty, especially those who find themselves to be unique in their departments or schools.

For much of the morning, fellows interview each other to discover their ideas about challenges of doing research and teaching as well as of being a minority faculty member. Using the Jigsaw cooperative learning technique, they share the results of their interviews, creating a summary of key challenges for new faculty in each of these areas. In discussing these challengesand in individually choosing their top three issues - they come to see that they have several common concerns across disciplines; they also begin to develop a peer-level support network and consider various ways in which the program can address their needs. After discussing readings relevant to academic success (e.g., Boice, 1991, 1993a; Felder, 1994; Martini, 1999a, 1999b; Moody, 2004), they refine their personal research and teaching agendas and define career-development strategies that will work in their individual circumstances.

\section{Workshops and Seminars}

Fellows' monthly workshops, panels, and meetings thus grow out of the retreat conversation and respond directly to the concerns and challenges the fellows identified. We choose workshop leaders from among the most respected, knowledgeable senior faculty and administrators, and involve former fellows as panelists in ways that require little time commitment from them. In conversation with invited speakers, panelists, and senior administrators, the fellows explore strategies for key career development issues such as:

- Building a support network across the university and broadening their connections

- Developing their research agendas and scholarly productivity

- Developing a high level of comfort in the classroom, including discussions of teaching about diversity and teaching diverse student groups

- Balancing teaching and research efficiently

- Nurturing constructive professional relationships, including strategies for broad professional recognition both nationally and internationally

- Blending university service with career progression

- Considering strategies proven successful for junior faculty and helpful to diverse faculty 
When appropriate, consultants, deans, associate deans, and department chairs are invited to participate, enabling all to learn more directly about each others' perspectives and concerns. Since most of the challenges anticipated by the first fellows fall into categories which coincide closely with those identified by the research literature, we hope that we can cultivate a pool of speakers over the years.

Some examples from the pilot year's program may help illustrate these interventions. High on the list of challenges noted at the first retreat were concerns about interdisciplinary collaborations. Since many fellows work across disciplines or have dual appointments across departments, they were interested in learning more about how to successfully negotiate multidisciplinary engagements. In a discussion with panelists from the humanities, science, and medicine, the fellows explored strategies for earning recognition of their interdisciplinary work in an environment that is still largely shaped by disciplinary paradigms.

The dinner conversation with senior administrators was one of the most highly praised meetings of the year. The vice president and provost, the vice provost for academic programs, and the co-chairs of the U.Va. President's Commission on Diversity and Equity answered the fellows' questions regarding university policies and promotion and tenure procedures. One fellow commented in his final report on the value of the exchange: "Very effective, hands down the highlight of this year's agenda. The insight and enthusiasm of the participants was special. This meeting brought much needed clarity on promotion and tenure issues." Another fellow found the meeting useful "not only because of what was discussed, but because it gave me the feeling that I could e-mail or walk up to any of these people in the future and raise concerns or questions I might have." Reactions from senior administrators strongly suggest that they in return make use of the opportunity to learn about the concerns of diverse junior faculty. One senior administrator reported in an email following the discussion that he found the meeting valuable because "it helps us to identify where we need to clear up some things."

At the fellows' request we also organized a family potluck for both EDF fellows and the university teaching fellows (junior faculty who have slightly more university experience). The potluck was one of the ways we addressed the issue of isolation that junior faculty, particularly women and minority faculty, often report (Boice, 1993a; Wilson, 2004). Almost all of the fellows had small children and welcomed the opportunity to expand their social and professional peer networks.

Other activities included an information exchange about publishing and research resources with the associate vice president for research enhancement 
and the University of Virginia Press acquisitions editor, as well as an afternoon tea following a university-wide teaching workshop. With a reception at the provost's pavilion, the fellows concluded the year in the company of deans, associate deans, department chairs, consultants, and program speakers and supporters.

\section{- Connections With Senior Consultants}

Through thoughtfully designed partnerships, fellows learn the ropes from senior consultants much more quickly than they would on their own. Research repeatedly shows the value of good and early mentoring (Boice, 1993a, 1993b; Moody, 2004). To choose appropriate mentors, faculty developers on the steering committee use their knowledge of the teaching and research interests, as well as the mentoring potential, of faculty volunteers. Whenever possible, we try to match fellows with one or two consultants from different departments and avoid replicating any mentoring that individual departments offer to their new hires. Combining that information with details supplied by consultants and fellows (information forms can be found at http://trc.virginia.edu/Programs/EDF/EDF.htm), we match each fellow with one or more senior colleagues who serve as teaching coach, research counsel, or university confidant for a fellow, depending on their experiences and interests.

- Research counsels help fellows develop promising and coherent research agendas and a strong professional standing in their field. We match research counsels to fellows based on parallels between their research interests and types of research experience and plans. Research counsels are thus more likely than other consultants to be matched with fellows from related disciplines.

- Teaching coaches help fellows develop their teaching skills and manage their courses efficiently and productively. The best teaching coaches are thoughtful about how and why they teach as they do, regularly analyze their teaching, undertake teaching innovations, and like to share ideas about teaching. We expect that teaching coaches and fellows will visit each others' classes and compare notes on teaching approaches and philosophies. Normally, teaching coaches work with fellows outside their own departments.

- University confidants help fellows get to know and feel comfortable within the university, outside their own departments. The best university confidants have had experiences (e.g., faculty senate, dean's or provost's 
promotion and tenure committee, department chair) through which they learned how their schools (or the college) and the entire university operates. They are willing to share insights gained from those experiences and help fellows understand and feel connected to the university beyond their departments. University confidants typically work with fellows outside their own departments.

Because new women and minority faculty in particular often hesitate to ask senior colleagues for their time (Moody, 2004), we strongly encourage consultants to initiate the first meeting and take the lead in setting up a regular monthly schedule. To help the consultants hit the ground running, the steering committee members meet with them as a group. In this setting, we give them information about the needs of incoming faculty, particularly of diverse faculty members, and share with them comments from former fellows about ways in which their consultants helped them. We discuss a short excerpt from Moody (2004) on good mentoring strategies; fellows read it as well. Finally, we encourage those consultants with successful previous mentoring experience to share what worked for them and those whom they mentored.

Admittedly, there is a great of deal luck involved in making good matches, even for someone who is very familiar with the volunteering senior colleagues. And we encourage both fellows and consultants to ask us for new arrangements if the initial pairing does not work. Judging from the final reports, however, both fellows and consultants found the relationships productive and rewarding. As one fellow describes her experience,

- "My consultants were wonderful! [My university confidant] made me aware of university politics and how to avoid unnecessary road blocks.... Most of all, she helped me think through my role as a wife, mother and professor. The juggling that this requires is exhausting, but so very rewarding. The key is not to keep all the balls in the air at all times, but to pick them up when they fall."

\section{Program Evaluation}

The steering committee evaluates the program in an ongoing manner in order to improve pilot activities and, eventually, to learn how the program influences faculty members' future professional success and tenured retention at U.Va. We are collecting evaluation data such as the following: 
- After workshops, fellows respond to open-ended questions, noting what was effective and recommending changes to better meet the program objectives.

- Presenters in workshops and seminars are asked for suggestions for future programs.

- At midyear, fellows and consultants complete a brief questionnaire asking them about the number and quality of their encounters and the usefulness of the workshops they attended and their recommendations for improvements.

- At the end of each academic year, both fellows and consultants summarize their experiences, highlighting program initiatives and discussion topics that proved especially beneficial and noting activities that could be improved.

\section{: Pilot Program Assessment}

It is difficult to evaluate the ultimate success of a three-year pilot program within its lifetime because the principal goal of diverse faculty retention can be measured only over a longer time period (the six years necessary to a normal promotion and tenure decision). Nevertheless, at the end of the third year we will seek feedback on the value and future direction of the pilot program from colleagues at peer institutions who have significant experience regarding diverse faculty retention.

In 2003, six of the eight fellows reported that the EDF Program had a very significant impact on their sense of connection to the university community. (The other two found the impact to be significant and rated it a 4 on a 5 -point scale, with 5 being "very significant" and 1 "none.") The fellows valued the time and attention they received from consultants, panelists, and senior administrators, as well as their connection to peers in other disciplines. One of the fellows put it this way: "The EDF Program reinforced my sense of being welcomed and valued; it broadened my awareness of the university outside my own and related disciplines; and it put faces to the names of highup people in the administration."

\section{Long-Term Assessment}

The long-term assessment project (2009-2010) will study the program's impact on the retention of fellows by surveying former fellows and a control group of faculty who did not participate in the program. We will collect data 
about these colleagues' interest in remaining at the University of Virginia, their sense of connection and collegial support, and their overall level of satisfaction with their career at the university. We will also ask for feedback on ways to improve the program.

\section{Questions to Consider in Setting up a Similar Program}

Before setting up a program such as this one, you may want to consider the following situational factors specific to your particular institutional structure and culture:

- How supportive are your upper-level administrators? How committed is the institution as a whole?

- What are the specific shortcomings that cause minority faculty members to leave? Exit interviews as well as interviews with faculty who remain may help you to assess the particular challenges of your institution.

- Who are the key supporters, and how can they be involved in shaping the program to address specific institutional needs?

- How can your institution convince new faculty that they are valued?

- What are the roles of mentors?

- How are they selected, involved, and trained?

- How are senior faculty and administrators best educated about the experiences of faculty from underrepresented groups?

- What are funding sources?

(For additional considerations regarding timing, content, and target audience of new faculty programs in general, see Fink, 1992.)

\section{Conclusion}

The ultimate goal of the Excellence in Diversity Fellows Program is that the university be so successful at retaining a diverse faculty population that critical mass is attained. At that point, we hope that the size of the program can be expanded to serve all interested incoming faculty, since all new tenure-track faculty face significant obstacles to success on various professional fronts (Sorcinelli, 1992). Fellows from the program's first year voiced enthusiasm 
about continuing the connections and about helping future fellows. We are including them in events and in planning as their time allows. Since we are in the second year of a three-year funding cycle, we are currently seeking future funding through the university's Office of Development and looking into grant possibilities.

It is very heartening and encouraging to witness the generous and enthusiastic support the Excellence in Diversity Fellows Program receives from the provost's office and our senior colleagues who serve as consultants and program speakers. Judging from the fellows' final reports, the pilot program was a great success in terms of the immediate impact on the fellows' sense of belonging and the meaningful connection to colleagues both junior and senior. It is our hope that these first positive experiences will translate into successful long-term careers at the University of Virginia.

\section{References}

Alire, C. A. (2002). The new beginnings program: A retention program for junior faculty of color. In T. Y. Neely \& K.-H. Lee-Smeltzer (Eds.), Diversity now: People, collections, and services in academic libraries (pp. 21-30). Binghamton, NY: Haworth.

Austin, A. (1990). To leave an indelible mark: Encouraging good teaching in research universities through faculty development. Nashville, TN: Peabody College of Vanderbilt University.

Boice, R. (1991). Quick starters: New faculty who succeed. In M. Theall \& J. Franklin (Eds.), New directions for teaching and learning: No. 48. Effective practices for improving teaching (pp. 111-121). San Francisco, CA: Jossey-Bass.

Boice, R. (1993a). Early turning points in professorial careers of women and minorities. In J. Gainen \& R. Boice (Eds.), New directions for teaching and learning: No. 53. Building a diverse faculty (pp. 71-80). San Francisco, CA: Jossey-Bass.

Boice, R. (1993b). New faculty involvement for women and minorities. Research in Higher Education, 34(3), 291-341.

Cross, T. (2003). The nation's colleges show a modest improvement in AfricanAmerican graduation rates, but a huge racial gap remains. Journal of Blacks in Higher Education, 41, 109.

Davis, A. M., \& Smith, M. J. (2004). Embracing diversity in pursuit of excellence. Report of the President's Commission on Diversity and Equity. Retrieved May 20, 2005, from the University of Virginia, Voices of Diversity web site: http://www.virginia.edu/uvadiversity/embracing_report04.html 
Felder, R. M. (1994). Things I wish they had told me. Chemical Engineering Education, 28(2), 108-109.

Fink, L. D. (1992). Orientation programs for new faculty. In M. D. Sorcinelli \& A. E. Austin (Eds.), New directions for teaching and learning: No. 50. Developing new and junior faculty (pp. 39-50). San Francisco, CA: Jossey-Bass.

Hale, F. W., Jr. (Ed.). (2004). What makes racial diversity work in higher education: Academic leaders present successful policies and strategies. Sterling, VA: Stylus.

Martini, K. (1999a). Making service count (a little): Guiding principles for junior faculty. Retrieved May 20, 2005, from the University of Virginia web site: http://www.people.virginia.edu/ km6e/Papers/service-essay-99.html

Martini, K. (1999b). Making your case: Strategies for an effective tenure package. Retrieved May 20, 2005, from the University of Virginia web site: http://www.people .virginia.edu/ km6e/Papers/make-case/

Moody, J. (2004). Faculty diversity: Problems and solutions. New York, NY: Falmer.

Morrissey, S. (2002). Academic diversity. Chemical and Engineering News, 81(34), 24.

National Science Foundation. (2000a). GEO 2000 full report (NSF 00-27). Retrieved May 20, 2005, from http://www.nsf.gov/geo/adgeo/geo2000/geo_2000_full_ report.jsp

National Science Foundation. (2000b). Women, minorities, and persons with disabilities in science and engineering: 2000. Retrieved May 20, 2005, from http://www.nsf.gov/sbe/srs/nsf00327/start.htm

Olsen, D., \& Sorcinelli, M. D. (1992). The pretenure years: A longitudinal perspective. In M. D. Sorcinelli \& A. E. Austin (Eds.), New directions for teaching and learning: No. 50. Developing new and junior faculty (pp. 15-25). San Francisco, CA: Jossey-Bass.

Sorcinelli, M. D. (1992). New and junior faculty stress: Research and responses. In M. D. Sorcinelli \& A. E. Austin (Eds.), New directions for teaching and learning: No. 50. Developing new and junior faculty (pp. 27-39). San Francisco, CA: Jossey-Bass.

Wilson, R. (2004, December 3). Where the elite teach, it's still a man's world. Chronicle of Higher Education, p. A8. 